\title{
Unpacking the 2-year age-gap provision in relation to the decriminalisation of underage consensual sex in South Africa
}

\author{
Z Essack, 1,2,3 MSocSci (Research Psychol), PhD; J Toohey, ${ }^{1,3}$ LLM (Medical Law) \\ ' HIV/AIDS Vaccines Ethics Group (HAVEG), University of KwaZulu-Natal, Pietermaritzburg, South Africa \\ ${ }^{2}$ Human and Social Development Programme, Human Sciences Research Council, Pretoria, South Africa \\ ${ }^{3}$ School of Law, University of KwaZulu-Natal, Pietermaritzburg, South Africa
}

Corresponding author: Z Essack (zessack@hsrc.ac.za)

\begin{abstract}
Over the past 24 years, the South African criminal justice system has undergone major transformations in relation to sexual offences, including sexual violence against children. More recently, there have been a number of developments to certain provisions in the law relating to sexual offences involving children. In response to the Teddy Bear Clinic Court Case and Constitutional Court ruling, sexual offences legislation related to underage consensual sex was amended. In this regard, the legislation now decriminalises underage consensual sexual activity between adolescent peers aged 12 - 15-year-olds. In addition, the law provides broader definitions for consensual sexual activity, including decriminalising consensual sex and sexual activity between older adolescents (above age of consent for sex, i.e. 16 - 17-year-olds) and younger adolescents (below the age of consent for sex, i.e. 12 - 15-year-olds), granted that there is no more than a 2-year age gap between them. One of the reasons for decriminalising consensual sexual activities between adolescent peers was because the expanded legislation cast the net for sexual offences so wide that the effects had far-reaching harmful impacts, particularly for girls, who would then be exposed to the criminal justice system. This paper focuses on unpacking the 2-year age-gap provision in SA legislation relative to selected better-resourced countries, including the rationale and the potential implications for adolescents (outside of the 2-year age gap provisions), for researchers, service providers and policy-makers. It concludes with some recommendations for law reform and further research.
\end{abstract}

S Afr J Bioethics Law 2018;11(2):85-88. DOI:10.7196/SAJBL.2018.v11i2.657

South African (SA) sexual offence legislation, like that of many other countries, has undergone numerous revisions, increasingly adopting a more liberal tone. This evolution in the law has aimed to ensure the protection of children from predatory sex with adults, while reflecting the realities of adolescent sexual experimentation. ${ }^{[1]}$

Some countries include age gap or close-in-age provisions to protect individuals who engage in consensual sexual activity with an adolescent below the age of consent, provided that the age difference is within the prescribed age range. ${ }^{[2]}$ In July 2015, the Criminal Law (Sexual Offences and Related Matters) Amendment Act No. 5 of $2015^{[3]}$ was enacted (the Sexual Offences Act), decriminalising underage consensual sexual activity (including penetrative sex) among adolescent peers aged $12-15$. Additionally, the amended law, decriminalises consensual sexual activity between older adolescents (above age of consent for sex, i.e. 16 - 17-year-olds) and younger adolescents (below the age of consent for sex, i.e. 12 - 15-year-olds), provided that there is no more than a 2-year age gap between them. These changes in the law do not affect the age of consent to sex, which remains at 16 years old..$^{[4]}$

This article describes current legislation regarding agegap provisions in SA and selected better-resourced countries. It considers the rationale for and objections to these provisions, and the implications for adolescents outside of these provisions, for researchers, service providers, and policy-makers. It concludes with recommendations for law reform and further research.

\section{Age-gap provisions for underage consensual sex}

Across the USA, the age of consent to sex varies between 16 and 18 years old. Most states have fixed age-gap provisions decriminalising sexual relations among adolescents, granted that they are within a certain age range. Age-gap provisions range from 2 to 6 years across the USA, but are typically 3 or 4 years. ${ }^{[5]}$ Some states also have Romeoand-Juliet provisions for sexual activity between adolescents when one participant is below the age of consent; such provisions either reduce penalties associated with such an offence or exculpate the crime. ${ }^{[5,6]}$

Countries such as Canada and Australia have nuanced approaches to close-in-age provisions. For example, Canada prescribes the age of consent to sex at 16 , with two close-in-age provisions. Firstly, sex with adolescents aged $12-13$ years old is decriminalised if the older partner is no more than 2 years older. Secondly, sex with adolescents aged 14 - 15 years old is decriminalised if the older partner is no more than 5 years older. ${ }^{[7]}$ It appears that the underlying principle is that of 
narrow age gaps for younger adolescents (closer to 12 years old) and wider age gaps for older adolescents. Such nuanced approaches take into account adolescents' evolving decision-making capacity.

Other countries, such as Finland, set the age of consent at 16 with no close-in-age provisions, but qualify that underage consensual sex is not punishable if the adolescents are similar in age and development.

Despite the variation across countries, it appears that legislators recognise the need to distinguish between (i) predatory adults who engage in sexual activity with adolescents below the age of consent, and (ii) adolescents (above the age of consent) who engage in consensual sexual activity with adolescents below the age of consent.

\section{Approach to the age-gap provision in SA's current sexual offences legislation}

Amendments to sections 15 and 16 of the Sexual Offences $\mathrm{Act}^{[3]}$ pertain to the decriminalisation of underage consensual sexual activity (including penetrative sex) (i) where both are between 12 and 15 years old; and (ii) between a 12 - 15-year-old and a 16 - 17-year-old, provided there is no more than 2-year age difference between them. ${ }^{[4,8,9]}$ Prior to these amendments, the law specified that a 17-year-old who engaged in consensual penetrative sex with a 15-year-old (despite not more than a 2-year age gap) could potentially be charged with statutory rape; this is no longer the case. However, if a 17-year-old has consensual penetrative sex with a 14-year-old, this could potentially be considered a sexual offence (statutory rape) because the age gap is more than 2 years.

It is important to note that the amendments to the Sexual Offences $\mathrm{Act}^{[3]}$ provide that if the Director of Public Prosecutions authorises prosecution for such an offence, the older adolescent (16 - 17-year-old) could be prosecuted. Consequently, children $<18$ years old are at risk of exposure to the criminal justice system and the associated harmful consequences, including having their names entered onto the sexual offences register. ${ }^{[10]}$ However, it may be argued that the fact that the Director of Public Prosecutions has discretion to prosecute provides an additional level of screening as protection for adolescents.

Table 1 below describes age spans for underage consensual sex and sexual activity, indicating where the risk of prosecution lies.

\section{Rationale for age-gap provisions}

The rationales for particular age-gap provisions vary - different contexts rely on different rationales (e.g. protecting the victim, decriminalising normative adolescent behaviour, protecting children from the criminal justice system) when specifying the age-span parameter. ${ }^{[1]}$ Generally, age-gap provisions rely on the premise that sexual activity between similarly aged peers is more likely to be

\begin{tabular}{lll}
\multicolumn{3}{l}{ Table 1. Current legal provisions on underage consensual sex } \\
\hline $\begin{array}{l}\text { Partner A age, } \\
\text { years }\end{array}$ & $\begin{array}{l}\text { Partner B age, } \\
\text { years }\end{array}$ & $\begin{array}{l}\text { Current legal provisions on } \\
\text { underage consensual sex }\end{array}$ \\
\hline $12-15$ & $12-15$ & Not an offence \\
12 & 16 or 17 & Offence; age gap $>2$ years \\
13 & 16 or 17 & Offence; age gap $>2$ years \\
14 & 16 & Not an offence \\
14 & 17 & Offence; age gap $>2$ years \\
15 & 16 or 17 & Not an offence
\end{tabular}

consensual than predatory. ${ }^{[1,2]}$ Age differences may arguably be used as a proxy to indicate power differentials between older and younger partners, with smaller differences indicative of more balanced power dynamics. ${ }^{[12]}$

In addition, adolescent sexual experimentation is considered developmentally normative, ${ }^{[13]}$ and fairly common; in fact, many adolescents, including in SA, may have sex before age $16 .{ }^{[14]}$ The task of legislators, therefore, is to protect adolescents from adult sexual predators, while ensuring adolescents' right to autonomy to participate in self-determined sexual activity. ${ }^{[15]}$ Age-gap provisions transfer criminal sanctions from the moral dilemma of underage sex per se, to a focus on the ages of the parties involved - capturing the sentiment that adolescent sexual experimentation is not fundamentally wrong. ${ }^{[16]}$

SA has taken a conservative approach in its selection of a 2-year age gap, reinforcing the idea that close-in-age consensual relationships are less likely to be coercive. ${ }^{[2]}$ This is substantiated by research which suggests an increased risk of sexual intercourse when young girls have older partners. ${ }^{[17]}$ The choice of a conservative age gap may also reflect public opinion. Empirical research in the USA indicates that respondents were more critical of scenarios involving larger age differences between partners, specifically 4- to 5-year (and greater) age gaps. ${ }^{[2]}$ Still, liberal age-span provisions arguably minimise the number of unjust prosecutions, ${ }^{[18]}$ and the US Model Penal Code proposes a 4-year age gap when decriminalising underage consensual sex. ${ }^{[19]}$

A major critique of age-gap provisions is the simplistic reliance on age difference as a proxy for coercion, with larger differences assumed as indicative of coercion, exploitation or undue influence. ${ }^{[20]}$ The narrow focus on age difference ignores the fact that multiple factors contribute to coercion and exploitation in adolescent sexual relationships, including power relations, gender norms and sexual and social experiences. ${ }^{[20]}$ Recent SA research with social workers found that in practice, the age difference between adolescent peers was one of several factors considered when making decisions about whether to report underage sex to authorities. ${ }^{[21]}$ However, under the law, age difference is the only consideration. ${ }^{[8]}$

An age differential cannot inherently reveal whether a sexual relationship is coercive or not - such a reductionist approach may inadvertently deflect from potentially coercive relationships among similarly aged peers. ${ }^{[22]}$ Recently published research with SA adolescents found that 'coerced sexual debut among young adolescents occurred mostly through sexual intercourse with peers, older adolescents and young adults, rather than with older adults'.[23] Despite these concerns, using age difference as a proxy for coercion has pragmatic benefits - it would be much more difficult to qualitatively explore consent in each case of underage sex. ${ }^{[22]}$

The amended law maintains the goal of protecting adolescents from predatory sex with adults, but inadvertently preserves a punitive measure for consensual peer sex where adolescents aged $16-17$ engage in sexual activity with adolescents aged $12-15$, when there is more than a 2-yea $r$ age gap. Resultantly, this leaves adolescents at risk to statutory rape prosecutions, exposing them to the criminal justice system ${ }^{[9]}$ Furthermore, while a sexual relationship between a 12- and a 15-year-old carries no criminal sanction, if the couple continue their relationship until the older adolescent turns 16 , this relationship would be considered a criminal offence that should be 
reported to authorities, resulting in the older adolescent being liable for prosecution. The 2-year age gap does not consider that adolescent relationships often begin during high school, where the ages of teens vary by 3 to 4 years. ${ }^{[24]}$

Further, in some countries age-discordant relationships are nonnormative; however, in SA, such relationships are a social reality. ${ }^{[24]}$ While the social and economic power imbalances arising from age discordancy may affect abilities to negotiate safer sex with older partners, some contend that not all relationships with large age spans are problematic. ${ }^{[8]}$ Some young girls specifically seek out older partners for security, as a result of the perception that older men make better lovers or for transactional sex purposes, which affects their HIV/AIDS risk. ${ }^{[9]}$

\section{Implications for SA researchers/service providers}

A key implication of age-gap provisions for researchers and service providers (e.g. psychologists, social workers, doctors) is that amendments have been expanded to include sexual penetration - this absolves providers of some of their mandatory reporting responsibilities. ${ }^{[8]}$ However, even when sex among minors under 18 is consensual, researchers and service providers need to be aware that they are legally obliged to report to the authorities where an adolescent is $12-15$ and the partner is $16-17$ with an age gap of more than 2 years at the time of the act. ${ }^{[9]}$

The question then is whether researchers and service providers will be required to actively identify the exact ages of both partners and report to authorities if they reasonably believe the age gap to be larger than 2 years, as is the case elsewhere. ${ }^{[25]} \mathrm{SA}$ authors have argued in favour of explicit knowledge of the age difference when reporting underage consensual sex. ${ }^{[26]}$

Researchers and service providers will also be ethically required to discuss with adolescents the limits to confidentiality, including regarding mandatory reporting responsibilities where there is more than a 2-year age gap between adolescents. ${ }^{[21]}$ This may have implications for research and for service provision, as adolescents may be reticent to disclose the age of their partners. In a servicedelivery context, this could mean that adolescents do not bring their partner in for sexually transmitted infection (STI) treatment (or other healthcare services), owing to concerns that they will be reported, therefore heightening the chance of their own reinfection.

\section{Conclusions and recommendations}

The amendment to SA sexual offences legislation pertaining to underage consensual sex is appropriate and in keeping with the Constitutional Court ruling. It also provides expansion of the closein-age defence to sexual penetration. The 2-year age-gap provision does not, however, consider that many young girls are involved in age-disparate relationships, ${ }^{[14]}$ nor does it protect all minors engaged in consensual sex from prosecution.

The conservative approach appears to be based on the rationale of protecting victims, especially if it is assumed that age disparities are an adequate proxy for power asymmetry and thus for coercion and exploitation. However, the reality is that even similarly aged relationships can be coercive, and healthcare providers will need to assess a host of other factors when making determinations.

The inclusion of a conservative age-gap provision leaves minors (children $<18$ years) vulnerable to prosecution, and may create barriers for adolescents in intergenerational relationships, especially young girls, from accessing sexual and reproductive healthcare services.

It is therefore recommended that law reform include a more nuanced approach to age-gap provisions, or that if the more conservative age difference is favoured, age be considered along with other criteria, such as maturity and relations of authority (e.g. where one party in the relationship has some authority over the other). This more flexible, holistic approach reflects some consideration of the 'best interests of the child' principle, including considering 'the child's age, maturity and stage of development, gender, background and any other relevant characteristic of the child! ${ }^{[21]}$ It is also recommended that more empirical research be conducted to better understand the dynamics of coercive and exploitative adolescent sex in the SA context.

The task of developing legislation to provide safeguards for adolescents from adult sexual predators, ensuring adolescents' engagement in sexual activity is self-determined and addressing social challenges related to high risk of HIV/STIs and teenage pregnancy is a national challenge.

Acknowledgements. The authors would like to thank the reviewers for their helpful feedback. Thanks also to Prof. Ann Strode and Dr Catherine Slack for their comments on drafts of this manuscript.

Author contributions. ZE conceptualised the paper. ZE and JT both contributed to the content of the paper and revisions of drafts.

Conflicts of interest. None.

Funding. The work described here was supported by the SA AIDS Vaccines Initiative (SAAVI) and the National Institutes of Health award (1RO1 A1094586) CHAMPS (Choices for Adolescent Methods of Prevention in SA). The content is solely the responsibility of the authors and does not necessarily represent the official views of SAAVI or the National Institutes of Health. This article does not necessarily reflect the views of any institution or committee or council with which the authors are affiliated.

1. Cocca C. Jailbait: The politics of statutory rape laws in the United States. Albany: SUNY Press, 2004.

2. Koon-Magnin SL. Adolescent sexual activity and statutory rape: A multi-method investigation. MA thesis. Pennsylvania: Pennsylvania State University, 2008.

3. South Africa. Criminal Law (Sexual Offences and Related Matters) Amendment Act Amendment Act No. 5 of 2015.

4. Mahery P. The 2015 Sexual Offences Amendment Act: Laudable amendments in line with the Teddy Bear clinic case. S Afr J Bioethics Law 2015;8(2):4-6. https:// doi.org/10.7196\%2FSAJBL.375

5. Davis NS, Twombly J. State legislators' handbook for statutory rape issues. Washington: American Bar Association Center on Children and the Law, 2000.

6. Kern JL. Trends in teen sex are changing, but are Minnesota's Romeo and Juliet laws? William Mitchell Law Rev 2013;39(5)1607-1622. http://open mitchellhamline.edu/wmlr/vol39/iss5/7

7. Wong JP. Age of consent to sexual activity in Canada: Background to proposed new legislation on "age of protection". Canadian J Human Sexual 2006;15(34):163-169.

8. Bhamjee S, Essack Z, Strode AE. Amendments to the Sexual Offences Act dealing with consensual underage sex: Implications for doctors and researchers. S Af Med J 2016;106(3):256-259. https://doi.org/10.7196\%2FSAMJ.2016.v106i3.9877

9. Strode A, Toohey J, Slack C, Bhamjee S. Reporting underage consensual sex after the Teddy Bear case: A different perspective. S Afr Bioethics Law 2013;6(2):45-47.

10. Essack Z, Toohey J, Strode A. Reflecting on adolescents' evolving sexual and reproductive health rights: Canvassing the opinion of social workers in KwaZuluNatal, South Africa. Reprod Health Matters 2016;24(47):195-204. https://doi. org/10.1016/j.rhm.2016.06.005

11. Koon-Magnin S, Ruback RB. The perceived legitimacy of statutory rape laws: The effects of victim age, perpetrator age, and age span. J Applied Soc Psychol 2013;43(9):1918-1930. https://doi.org/10.1111/jasp.12131 
12. Raiford JL, Wingood GM, DiClemente RJ. Prevalence, incidence, and predictors of dating violence: A longitudinal study of African American female adolescents. J Womens Health 2007;16(6):822-828. https://doi.org/10.1089/jwh.2006.0002

13. Gevers A, Mathews C, Cupp P, Russell M, Jewkes R. Illegal yet developmentally normative: A descriptive analysis of young, urban adolescents' dating and sexual behaviour in Cape Town, South Africa. BMC Int Health Hum Rights 2013;13(1):31. https://doi.org/10.1186/1472-698X-13-31

14. Shisana O, Rehle T, Simbayi LC, et al. South African National HIV Prevalence, Incidence and Behaviour Survey, 2012. Cape Town: HSRC Press, 2014.

15. Graupner H. Sexuality and human rights in Europe. J Homosexuality 2005;48(34):107-139. https://doi.org/10.1300/J082v48n03_07

16. Fischel JJ. Per se or power - age and sexual consent. Yale J Law Feminism 2010;22(2):279-341

17. Gowen LK, Feldman SS, Diaz R, Yisrael DS. A comparison of the sexual behaviors and attitudes of adolescent girls with older vs. similar-aged boyfriends. J Youth Adolescence 2004;1;33(2):167-175. https://doi.org/10.1023/B:JOYO.0000

18. Warner K. Setting the boundaries of child sexual assault: Consent and mistake as to age defences. Melb Uni Law Rev 2012;36:1009-1036.

19. Smith BL, Kercher GA. Adolescent Sexual Behavior and the Law. Texas: Sam Houston State University, 2011.
20. Brand D. Sugar, spice and criminalised consent: A feminist perspective of the legal framework regulating teenage sexuality in South Africa. S Afr J Human Rights 2013;29(2):193-218.

21. Essack Z, Strode A. The mandatory reporting of consensual, underage sex: Knowledge, practices and perspectives of social workers in KwaZulu-Natal. S Afr J Bioethics Law 2015;8(2):21-25. https://doi.org/10.7196\%2FSAJBL.435

22. Oberman M. Regulating consensual sex with minors: Defining a role for statutory rape. Buff Law Rev 2000;48:703-784.

23. Richter L, Mabaso M, Ramjith J, Norris SA. Early sexual debut: Voluntary or coerced? Evidence from longitudinal data in South Africa - the Birth to Twenty Plus study. S Afr Med J 2015;105(4):304-307. http://dx.doi. org/10.7196\%2FSAMJ.8925

24. Leclerc-Madlala S. Age-disparate and intergenerational sex in southern Africa: The dynamics of hypervulnerability. Aids 2008;22(Suppl 4):S17-S25. https://doi. org/10.1097/01.aids.0000341774.86500.53

25. The Northern Territory Government Department of Health. Under Age Sexual Activity. PHC Remote Guideline, 2015. Darwin: NTGDoH, 2015.

26. Bhana A, Swartz S, Davids A. Standards for the reporting of sex/sexual activity of minors in a research context. S Afr Med J 2010;100(10):642-644.

Accepted 21 October 2018 